\title{
Research on Visual Communication in Cultural and Creative Industry - Taking Taiwan as an Example
}

\author{
Shuluan $\mathrm{Fu}$ \\ Media Science School \\ Northeast Normal University \\ Changchun, China
}

\begin{abstract}
The cultural and creative industry originated in the United Kingdom in 1979. After decades of development, it has become an important industrial development model in the world economy, and it is one of the key fields of China's creative economy construction. Taiwan's cultural and creative industries have certain representativeness in the world, especially under the spread of Chinese-language context. So it is a case of cultural and creative industries that domestic scholars should study and interpret in depth. This has a good reference for the international cultural exchanges and communication of Chinese civilization. It can also help to improve the healthy development and strength of the Chinese cultural and creative industries, and thus can provide assistance for the "cultural renaissance" of the Chinese nation. Taking visual communication as the research perspective, this paper mainly presents the data on policy and management of the cultural and creative industry and conducts specific analysis on some cultural and creative cases with Taiwanese characteristics. Based on the discovery of the experiences in the development of Taiwan's cultural and creative industries, this paper analyzes the advantages and characteristics of Taiwan's cultural and creative industry from multi-dimensions of culture, color and experience visual communication. Therefore it can provide mature experience for the development of the Chinese cultural and creative industries, in order to truly find the "cultural confidence" of the Chinese nation.
\end{abstract}

Keywords-Taiwanese cultural creation; visual communication; culture; experience; color

\section{INTRODUCTION}

In today's world, no matter it is countries, communities or individuals, are all paying attention to the research of cultural and creative industries. New ideas are being created every day, and new creative economies are being developed in every moment. The cultural and creative industry has been displaying the appearance of different civilizations and cultural personalities of human beings with rich and different visual forms, and constantly producing new visual forms in different countries, regions, cultural groups and economic models. It is all these differences that make our visual communication context today so diversified and interesting. With all these differences in civilization, geographical condition, cultural variation and spiritual world, somehow we share quite a lot in the development of visual communication in our cultural and creative industries. In this paper, a sample of cultural creation in the Chinese world Taiwan is used to interpret the visual communication cases with Oriental characteristics in the cultural and creative world, in order to add a touch of color to the current cultural and creative research.

\section{ORIGIN OF THE CREATIVE INDUSTRY}

According to the report of UNESCO, "International Flows of Selected Cultural Goods and Services, 1994-2003", the total trade in global cultural goods increased from $\$ 39.3$ billion in 1994 , to $\$ 59.2$ billion in 2002 , almost growing in multiples. And in 2005, the United Nations Conference on Trade and Development pointed out that the cultural and creative industries have reached 1.13 trillion US dollars in the global market, with an annual growth rate of $5 \%$ to $20 \%$. ${ }^{1}$ It can be seen from the footnotes that the cultural and creative industries have gradually occupied an important position in the global business market, with huge economic potential. It is the main internal cause of the vigorous development of cultural and creative industries in various countries and regions.

The creative industry first appeared in the United Kingdom. In 1979, the British government began to promote the "creative industry" policy and effectively upgraded the domestic economy. After that, the governments of other countries in the world began to follow suit. Economic development led by culture and creativity is not only a process of rethinking culture with economic thinking, but also a rethinking of the human spirit and a re-examination of human wisdom and creativity. The ingenious combination of cultural power and commercial power is required. On the one hand, it enhances the value of culture itself; on the other hand, it also gives new souls to commodities, creating a new connection between culture and consumption. Under the modern trend of emphasizing the establishment of personal life style and life aesthetics, creativity has become the main driving force in the social and economic transformation of this century, and the cultural and creative industry has become the leader industry in the new century.

"Consumption" is no longer just a universal life behavior of modern people, but also represents the economic and

UNESCO, International Flows of Selected Cultural Goods and Services, 1994-2003 (Montreal and Paris: UNESCO, 2005). 
living affluence of a country or a region, and becomes a trend with the concepts of the aestheticization of everyday life and personal life style. The cultural symbols and symbolic content of commodities has become the main reason for consumption overwhelming the value of its use. Behind many consumption behaviors, it is not the functional demand of people for things, but the demand for beauty or other values of things that promotes purchase and produces consumption

As early as the 17th century in England, the artist William Morris tried to restore the production mode of traditional handicraft production in the face of standardized products made in mass production of mechanical equipment. But the hand-made furniture ornaments he designed for its high value can only circulate in the middle and upper class thus cannot be purchased and consumed by the mass. But the wave of the craft movement has underscored an aversion to the mass reproduction of products in modern industry. Through the preference for primitive crafts, it can be seen that goods which provide aesthetic experience, rather than those manufactured in a standardized mode of production, lacking in individuality and aesthetic taste, are more favored. With the advent of modern consumption society, commodities are no longer just commodities for most consumers. They become "works" or "works of art" which can not only meet our needs of using, but also enrich our daily life and give us spiritual satisfaction and pleasant feelings. The symbolic value of goods has become the focus of public concern. ${ }^{2}$

To revitalize the British economy and increase the gross domestic product, Tony Blair, the prime minister of UK, established the Department for Culture, Media and Sport (DCMS) in 1997, aiming to promote the creative industry. And in 2001, DCMS Identified 13 UK creative industries, including advertising, architecture, art and antique markets, craftsmanship, design, software and computer services. Since the implementation of the policy, the output value of the industry has reached 112 billion pounds in 2001, accounting for $8.2 \%$ of the GDP, and the export value is as high as 10.3 billion pounds. According to a report of the National Endowment for Science, Technology and the Arts (NESTA) in 2006, the global market value of the creative industry was raised from $\$ 831.3$ billion to $\$ 1.3$ trillion from 2000 to 2005 .

${ }^{3}$ In 2004 , the UK's GDP exceeded 7\% (the data before the industrial sector adjustment), and the Gross Value Added (GVA) reached $7.3 \%$, more than double of the original. The huge economic benefits of the creative industry make relevant authorities invest more budget on the development of the industry. In a report "Culture and Creativity in 2007", DCMS wrote that, In the past decade, Britain's budget in the field of culture and art has increased by $73 \%$, from 18.7 billion pounds in 1997 to 412 billion pounds in 2006 and 2007 , with specific policies to cultivate creative talents in the

Chiu Shu-yi, London creative industry development road, economic daily, Taiwan, January 20, 2007, 9th edition. (in Chinese )

UNESCO, International Flows of Selected Cultural Goods and Services, 1994-2003 (Montreal and Paris: UNESCO, 2005). cultural and creative industry. ${ }^{4}$ It can be seen that the development of cultural and creative industries first needs the support of the state and policy, which is proved by the development cases of many national cultural innovation industries.

\section{OVERVIEW OF TAIWAN CULTURAL AND CREATIVE INDUSTRY}

Taiwan has put forward the conception of "cultural industrialization and industrial culture" in the cultural industry seminar in 1995, but it applied only to the "Integrated community development" policy at that time. Only when the Britain, South Korea and other countries successful promoted national culture and economic development through the cultural and creative industries, the Taiwan government began truly value the cultural and creative industries. In the "Challenge 2008: national development plan" in 2002, Taiwan listed cultural and creative industries as one of the key promotion projects of Taiwan. With the improvement of education level in Taiwan, the transformation of economic structure, the gradual shift of traditional manufacturing industry, and the development of local science and technology industry, "knowledge" has become Taiwan's main competitiveness in economic development and international market. In 2000, the Taiwan government raised the goal of "Taiwan Double" on the basis of knowledge economy, aiming to triple the domestic production of every Taiwan citizen within ten years. In the two plans of "challenge 2008" and "Two Trillion \& Twin Star" in 2002, the cultural and creative industry as well as the digital content industry were listed as the important national development plans.

In 2009, in view of the transformation of Taiwan's cultural and creative industry in the second stage, the Taiwan government proposed "creative Taiwan - action plan of cultural and creative industry development" (2009-2013) based on copying the slogan of "creative Britain". This plan focused on the current advantages and potential, difficulties and industrial demands of the development of cultural and creative industries in Taiwan; it put forward the promotion strategy, hoping to achieve the vision of "Taiwan as a base to expand the Chinese language market and enter the international market" and to build Taiwan into the confluence center of Asia-Pacific cultural and creative industries. The strategy is divided into two sectors: "environmental reconditioning" and "flagship industry", which are respectively in charge of the Council for Cultural Affairs, the information bureau and the ministry of economy. At the same time, the Government Information Office of Taiwan made the "Plan to revitalize the pop culture industry"(2008-2011), including "The sprint plan for popular music industry", "Sprint plan for graphic publishing industry", "sprint plan for Digital publishing industry", "The sprint plans for film industry's service sector sprint plans", "The sprinting plan for television industry" as well as "Flagship plans for the TV content industry". \$1.28 billion

\footnotetext{
4 DCMS, Culture and Creativity in 2007 (London: Department for
} Culture, Media and Sport, UK, 2007). 
were to be invested help practitioners make the transition to international markets. ${ }^{5}$ As can be seen above, the dominant power of the government is the most important and effective factor in Taiwan's cultural and creative development.

The cultural and creative industry in Taiwan has relatively standard and reasonable management with its competent authorities are divided according to the property of industrial categories. For example, the CCA is responsible for cultural and arts related industries; the press bureau is responsible for media related industries; the ministry of economy focuses on design, creativity and digital technology, In the process of the plan promotion of the cultural and creative industry, the CCA, taken as an example, in the first stage from 2003 to 2007, the plan is to set up five creative and cultural parks, including Taipei, Taichung, Chiayi, Tainan and Hualien; to assisting arts and cultural workers in entrepreneurship; to make creative arts industry plans to assist in the industrialization of artistic creation, enhance the international competitiveness and sustainable value of Taiwan's artistic creation, and cultivate talents; to combine the advantages of Taiwan's technology and industrial plans to liven up local economy and local industrial upgrading by holding local festivals or cultural and art exhibitions. As for the arrangement of the planned budget, the creative cultural parks had the highest share of 1.461 .8 billion Yuan, accounting for $59.44 \%$, followed by the traditional technology plan, accounting for $14.29 \%$. The technology industry gave the most output value of 38 billion per year, accounting for $80 \%$ of the production value of the arts and culture industry. Following the plan of the first stage, the plan for the period from 2008 to 2011 includes strengthening industrial environment development, technological creative industry development and promotion of creative culture park. ${ }^{6}$ Scientific management has brought good development to the cultural and creative industry in Taiwan.

Today's world, with the transformation of the social structure and industrial forms, has gradually developed a special economic development pattern, which is the an economic power that is based on human knowledge and creativity, assisted by technological process of the times and integrates the uniqueness of national or city culture through the industrial management thinking. This economic form based on culture and creativity can be regarded as the rediscovery of humanistic cultural spirit after the industrial revolution, which is the cultural and Renaissance movement in the 21 st century. ${ }^{7}$ In the development of cultural and creative industry in Taiwan, "the rediscovery of humanistic cultural spirit" is omnipresent. Whether it is the development

\footnotetext{
The Council for Cultural Affairs, creative Taiwan -- action plan for cultural and creative industry development 98-102, Taipei: Council for Economic Planning and Development, Council for Cultural Affairs, Government Information Office, 2009, pp. 5-11. (in Chinese)

Council for Cultural Affairs, the second phase of the cultural and creative industry development plan (97-100 years), Taipei: Council for Economic Planning and Development, 2008. (in Chinese)

Li Tianduo, cultural and creative industry reader: creative management and cultural economy, Taipei: Yuan-Liou Publishing Co.,Ltd., 2016.10. 47. (in Chinese)
}

of cultural and creative products or the collection of multidimensional exhibitions, as well as in other related fields the attention to people's inner heart becomes the center of culture and creativity. Such "humanistic and cultural spirit" plays a very important leading role in the aesthetics and consumption of the public.

\section{INFORMATION ABOUT VISUAL COMMUNICATION}

The research result of Dr. Albert Mehrabian, a famous psychologist at UCLA, shows that, when people communicate through language, $7 \%$ of the information comes from the other person's language, 38\% comes from his way of talking (tone, intonation, etc.), and 55\% comes from facial expressions. This means that in the process of interpersonal communication, $55 \%$ of the information is obtained through vision. From the perspective of wider mass communication, there are also results showing that visual information accounts for more than $83 \%$ of all perception information of human beings. In today's consumer society, the rich material culture fills the world of human perception. The importance of visual communication is beyond doubt in the mass information that the masses are confronted with. But the reality that we should face is that the world around us has begun to focus on vision as the main medium and center. Our understanding of the world is no longer through words, but more through visual information. As communicators, better use of visual information can help us achieve better communication effect. Experiments by New York university psychology expert Jerome Bruner show that people can remember 10 percent of what they hear and 30 percent of what they read but80 percent of what they see. ${ }^{8}$ So, visual communication plays an important role in human information communication. The effect of information communication often depends on the control and mastery of visual communication.

Currently, the definition and interpretation of Visual Communication have multiple academic perspectives, including: design art, communication, semiotics, philosophy and psychology. According to Professor Zhang Haoda of Peking University, "in a highly information-intensive urban society, visual communication is closely related to the circulation, distribution and exchange of various 'information 'systems and opportunities. Its human function and social function deepened the connection between man and nature, man and society, and man and man. ${ }^{9}$ This kind of connection may be what we need to pay special attention to in the visual communication of cultural and creative industry. At present, there are abundant interpretations and researches on such key words as visual communication, visual communication and visual culture, but no conclusion has been reached. The author holds the view that the phenomenon of visual communication itself has a distinct interdisciplinary nature. From ancient to modern times, many scholars have different

[America] Paul m. Lester, visual communication: image carrying dynamic information, Beijing: Communication University of China press, 2003.

9 Zhang Haoda, visual communication: information, cognition, and interpretation, Beijing: Peking University press, 2012.10, page 9. (in Chinese) 
academic backgrounds, among which there are some master scholars or experts, which this article will not elaborate. For the cultural and creative industries involved in this study, the author sets the research perspective in the fields of design art, culture and branding for the time being. This article mainly focuses on the visual communication properties of the dominant brands and cases in the cultural and creative industry in Taiwan, including the visual characteristics of cultural, color and experience.

\section{Visual COMMUNiCATION IN THE CULTURAL INDUSTRY OF TAIWAN}

\section{A. Cultural and Visual Culture in the Creative Industrial Park}

The visual communication in Taiwan's cultural and creative industrial park has very distinct cultural characteristics. From the design of the space to the development of the product to the exhibition of the art activities and other details, history and culture intermingle can be seen everywhere. No matter how the visual language (poster advertisement, film and television propaganda film, installation art, etc.) changes, its content is always cultural. The external characteristics of its vision actually highlight the role and influence of its cultural internal forces, and also constitute a kind of visual culture.

The cultural and creative industrial park in the world originated from Europe and America in the 1990s. Many cities have listed it as the planning focus of urban regeneration policy and vigorously promoted the rational reuse of idle space. Taiwan scholars believe that "the creative cultural park is located in a clear and limited space; in addition to urban activation, as a cultural creative industries incubator, the creative cultural park have the function of both the cultural production and consumption. It can not only maintain the cultural characteristics of the space, but also generate economic scale conducive to industrial development." ${ }^{10}$ The Huashan 1914 creative culture park Taiwan was once the old winery of the public sale office. Taipei's old winery, founded in the 1920 s, closed in 1980 because of a change of government, was resurrected by the art world until in 1990. Through various methods of lobbying, organization and other actions, the unused space is utilized again to make full use of its possibilities and transformed into Huashan 1914 creative culture park (hereinafter referred to as Huashan Culture Park).

Huashan creative culture park is a typical case of Taiwan industrial creative culture park, which is also the most cultural creative culture park. The uniqueness of Huashan creative culture park can be felt from the evolution of its history. Inside the park, there is a long corridor of Huashan's history and culture, which spreads its unique cultural personality in the form of both pictures and texts. The combination of a longer historical story and real architectural space gives all viewers a taste of culture and history. While

10 Xia Xueli, editor-in-chief, introduction to cultural and creative industry, Taipei: Wu-Nan book publishing co., LTD., March, 2011, page 486. (in Chinese) being attached to wonderful creative culture products, viewers can feel the real impression of history through the old factory buildings, old walls, and even some old metal parts and mottled traces left in the old wineries everywhere. The park is positioned as: cultural and creative industry, interdisciplinary expression of art, shaping of the aesthetic style of life. Behind its advanced and dynamic model of modern cultural and creative industry, there is full respect for history and culture and spiritual backtracking. While letting young people find joy of life by being fashionable, edgy and experimental "cool", Huashan's old factory gives them the maximum tolerance and contrast. It is such visual impact of the charm of culture and the depth of history that become the most appealing visual sign of Huashan Park.

\section{B. Color in Exhibition Communication}

In the construction projects of cultural and creative industry in Taiwan, there were a large number of artistic exhibitions with rich artistic spirits being held frequently. Governments, companies, art groups, schools, research institutes, and even individuals hold various types of exhibitions, and a Paul Smith global tour in June 2017 became a visual feast for Taipei Born in 1946, Paul Smith, known as "British design wizard", is a world famous fashion designer. Themed as "HELLO, MY NAME IS PAUL SMITH: British design wizard PAUL SMITH world tour 2017", this exhibition consisted of not just the important works in his life, but also a wonderful collection of the design masters' life. This collection included hundreds of masterpieces and even imitates the design scheme and real materials used in the first store and all stores of Paul Smith's clothing brand. Meanwhile, Paul Smith's design studio is copied to the site. The exhibition site adopts decorative space design style and completely artistic visual communication language. With a rich and admirable aesthetic perspective, it introduces the wonderful life of costume design master Paul Smith and his outstanding artistic achievements. However, what is most striking is the color in the visual communication of the whole exhibition. This exhibition used the beautiful color of pink as the dominant tone. In people's visual cognitive habits, pink has a female flavor, and its meaning of communication is often referred to the subject or commodity related to women. The "Paul Smith" brand has women's clothing; its men's clothing also has a large proportion, though. At the same time, Paul Smith, as the world's top fashion designer, has also been engaged in a variety of trans-boundary designs and creations, including automobiles, sportswear, stationery, cloth, etc. This Paul Smith world tour had tremendous innovation and breakthrough from the respective of color, and perhaps the "anything-but-ordinary" way is the best embodiment of the Paul Smith design spirit.

The integrated pink spread throughout the exhibition: from exhibition posters, ticket booths, tickets, on-site gifts, to the layout design of illustrative text in the exhibition space, the interactive space elements on the spot, and the display color of artistic works occasionally interspersed in the space, etc. The echoes of many details employed pink, the color full of character, subtly and implicitly, therefore everyone in the 
audience is imperceptibly affected by the vision (there are many young people taking photos and participating in the interaction). So it can be seen that the success of this exhibition cannot be inseparable from the bold use of pink as the main color symbol in visual communication. This is in sharp contrast to the confusion of colors in visual communication in the Mainland China, which is only for peer researchers to ponder and reference.

It is worth mentioning that the location of the Paul Smith 2017 tour exhibition in Taipei was selected in the Huashan creative culture park, whose old grey walls and greencovered pavilion appearance bring a very good contrast and contrast to this exhibition. The simple industrial historical buildings form a striking contrast with the gorgeous costumes and art paintings, thus producing a strong visual impact. And the dim lighting inside the exhibition hall completely weakens many visual elements outside the exhibition. All these let every audience focus on the charm of Paul Smith with the dominant color pink.

\section{Experience in Cultural and Creative Brand}

"Wooderful life" is a famous Chinese music box brand in Taiwan with a huge product line. On the official website, the elaboration of its brand concept is as follows: "the hand knob allows the spring to drive the charming sound and interests, the dynamic lasting sensation, hidden in the simple beauty of life; 'Wonderful' meaning 'splendid', Wonderful translation of contemporary wooden craft ideas. According its meaning it is called 'wooderful life"'. Wooderful life presents "the pure beauty of life" through the elaborately made wooden musical box products with original wooden materials. The wood materials they use are legally cultivated in Europe, America, Canada and New Zealand. Its certificate of origin for sustainable operation of forest farm is a guarantee that "Wooderful life" will not destroy the forest due to economic logging. At the same time, they strictly implement the production process of "high sampling rate", to effectively reduce wood waste, and guarantee to make good products and provide good experience under the concept of "lowcarbon, environment-friendly and nature friendly". The rich and environmental-friendly product series makes every consumer feel like returning to the simple and beautiful childhood when starting the manual spring. Almost anyone who has heard of wooderful life's music boxes will be impressed by the natural, authentic and beautiful music options available in music boxes. The good experience of the product itself has brought great attraction to children and teenagers in particular. Many consumers are deeply impressed by this experience, thus bringing good reputation and sales performance to wooderful life.

The space design of the "wooderful life" boutique also fully reflects the experiential features. In the visual design of the space, a large number of trees, wood fences, artificial grassland and other visual elements that echo with the brand are adopted, so that all the consumers when entering the boutique, as if entering the music and happy "life forest". They are all infected by the "natural", "simple", "beautiful", "craft beauty" contained in Wooderful life both visually and audibly. At the same time, there is a special experience area in the store where you are free to choose the music of your favorite music box. Of course, you can also be provided customized services for the music box products. Consumers need simply wait for a few days to receive their favorite, custom-made music boxes, tailored from the design to music This kind of experiential marketing with strong advantages fully and appropriately reflects the personality and quality of the "wooderful life" brand. It can be said that "wooderful life" has become a unique landscape in the cultural and creative industry in Taiwan and has made a good cultural and creative brand.

\section{CONCLUSION}

Taiwan's cultural and creative industry is full of excellent cases, the advantages of which can be concluded as follows: Firstly, the government's support, policy support and multiplatform construction have brought the upsurge of cultural innovation to Taiwan. From government administration departments at all levels to every ordinary citizen, all of them have realized that the development of cultural and creative industry is the most important foundation and indicator of local economic development. Therefore the great impetus of the whole society is the necessary guarantee and important foundation of Taiwan cultural and creative development. Secondly, scientific management experience is a booster for the development of cultural and creative industries. In Taiwan, there are various exhibitions and cultural activities almost every week. While enlivening the life of citizens, it has greatly improved the research level and scientific management level of the whole cultural and creative industry, including visual communication, brand awareness, integrated communication, art experiment, pop culture, humanistic history and so on. With new increasing hot spots new methods and experiences keeps coming out to guide the healthy development of cultural and creative industry More writers, scholars, artists, entrepreneurs and other elite groups jointly contribute their ideas and Suggestions for the development of the cultural and creative industry. So with abundant creative talents and excellent creative environment, economic benefits are also transformed more rapidly. Finally, the love of knowledge and culture is the most important factor for the rapid development of cultural innovation in Taiwan. The 24-hour business of the eslite bookstore is the best reflection of Taiwan's cultural atmosphere. People's desire for knowledge, obsession for art and respect for innovation and creation are the real forces behind the development of the cultural and creative industry. People's desire for knowledge, obsession for art and respect for innovation and creation are the real forces behind the development of the cultural and creative industry. The improvement of the public's aesthetic taste, artistic power and creativity can be placed into every day and every detail of life, which is also the meaning of life aesthetics and visual communication. As an individual, when he loves beauty and understands beauty, he is bound to have some requirements in the aspects of clothing, food, residence and travel, and the development of Chinese cultural and creative industry will is gradually entering blissful circumstances. 


\section{REFERENCES}

[1] UNESCO, International Flows of Selected Cultural Goods and Services, 1994-2003. (Montreal and Paris: UNESCO, 2005).

[2] Chiu Shu-yi, London Creative Industry Development Road, Economic Daily, Taiwan, January 20, 2007, 9th edition. (in Chinese)

[3] DCMS, Staying Ahead : The Economic Performance of the UK's Creative Industries (London: Department for Culture, Media and Sport,UK,2007) .

[4] DCMS, Culture and Creativity in 2007 (London: Department for Culture, Media and Sport, UK, 2007).

[5] Council for Cultural Affairs, Creative Taiwan - Action Plan for Cultural and Creative Industry Development Program 98-102, Taipei: Council for Economic Planning and Development, Council for Cultural Affairs, Government Information Office, 2009, pp. 5-11.(in Chinese)

[6] Council for Cultural Affairs, Second Phase of Cultural and Creative Industry Development Plan (97-100 years), Taipei: Council for Economic Planning and Development.(in Chinese)

[7] Li Tianduo, Reader of Cultural and Creative industry: Creative Management and Cultural Economy, Taipei: Yuan-Liou Publishing Co.,Ltd., 2016.10. (in Chinese)

[8] [America] Paul M. Lester, visual communication: image carrying dynamic information, Beijing: Communication University of China press, 2003

[9] Zhang Haoda, Visual Communication: Information, Cognition, Interpretation, Beijing: Peking University press, 2012.10, page 9. (in Chinese)

[10] Xia Xueli, editor-in-chief, introduction to cultural and creative industry, Taipei: wunan book publishing co., LTD., march, 2011, page 486. (in Chinese) 